\title{
Superando riscos na atividade física relacionada à saúde
}

\author{
Edgard Matiello Júnior* \\ Aguinaldo Gonçalves** \\ Jéssica Félix Nicácio Martinez ${ }^{* * *}$
}

\begin{abstract}
Resumo: A lógica dos fatores de risco que predomina nas investigações epidemiológicas do campo da Saúde vem sendo reproduzida na Educação Física, especificamente na tendência hegemônica denominada Atividade Física relacionada à Saúde. Neste trabalho o objetivo é apresentar e discutir principais marcos históricos e destacar efeitos desse paradigma nesses campos de conhecimento. Ao final, será apresentada uma forma de apropriação de Epidemiologia Crítica como ilustração de tentativa de superação junto a trabalhadores do setor bancário.
\end{abstract}

Palavras-chave: Atividade Física. Saúde Pública. Fatores de Risco. Epidemiologia.

\section{INTRODUÇÃO E OBJETIVO}

Em trabalhos anteriores (MATIELLO JÚNIOR; GONÇALVES, 2001, 2004) recuperamos aspectos da produção de conhecimentos e tendências das hegemonias do campo denominado Atividade Física relacionada à saúde, analisando sua sustentação em recortes limitados de disciplinas de bases biológicas e comportamentais e tem como objeto a aptidão física como principal (praticamente o único) mediador com a saúde.

Além disso, enfatizamos que do amplo espectro de problemas da Saúde Coletiva brasileira, esta tendência hegemônica assume

\footnotetext{
* Doutor em Ciências do Esporte. Grupo Vivendo Educação Física e Saúde Coletiva (NEPEF/ UFSC). Florianópolis, SC, Brasil. E-mail: edgard@cds.ufsc.br

" Professor Titular de Saúde Coletiva e Atividade Física, Faculdade de Educação Física da Unicamp. Campinas, SP, Brasil. E-mail: aguinaldogon@uol.com.br

** Mestre em Educação Física. Grupo Vivendo Educação Física e Saúde Coletiva (Nepef/ UFSC). Florianópolis, SC, Brasil. E-mail: jessicafelix01@yahoo.com.br
} 
compromisso com a pauta de pesquisa importada de outros centros de conhecimento (combate ao sedentarismo e prevenção de doenças crônico-degenerativas), a qual, apesar de importante, limita a atuação política e científica da Educação Física, na medida em que estabelece prioridades de forma descontextualizada sobre a saúde de nossa população; estimula relações verticalizadas da academia sobre o conhecimento popular e sobreposição da atuação técnica em detrimento da educativa em perspectiva crítica. Finalmente, tratamos também de apresentar aspectos éticos de processo de alinhamento intelectual orientado para atender necessidades de criação de novos mercados.

Buscando dar seqüência e aprofundamento a algumas dessas questões, neste trabalho o objetivo é apresentar e discutir bases teórico-metodológicas do paradigma de risco instalado hegemonicamente no campo da Saúde e que têm marcada influência sobre a produção de conhecimentos da Educação Física. Serão reconstruídos os principais marcos históricos e destacados efeitos de sua aplicação. Ao final, serão apresentados elementos da Epidemiologia Crítica como alternativa de superação do enfoque de risco.

\section{Sobre CAUSALIDADE E O PARADIGMA DOS FATORES DE RISCO}

$\mathrm{Na}$ epidemiologia tradicional, aspecto central é desvelar a relação que se estabelece entre causas (exposição a fatores) e seus efeitos (doenças), considerando-se associação causal quando a alteração na freqüência (ou intensidade) de um dos elementos acarretar mudança no outro. É a essa forma de compreender o processo de determinação da saúde das pessoas que chamamos causalidade, cujo emprego pode se dar tanto no âmbito individual (da clínica), quanto no coletivo (ALMEIDA FILHO, 2000).

No decorrer da história da humanidade as explicações às causas das doenças têm sido bastante diversificadas (ROSEN, 1994), com sua construção limitada não apenas ao alcance do conhecimento humano, mas, sobretudo ao "modo predominante de interpretar as relações com a natureza e indivíduos entre si"

Movimento, Porto Alegre, v. 14, n. 01, p. 39-61, janeiro/abril de 2008. 
(SABROZA, 1994, p.7). Esta afirmação tem alguns significados importantes, dentre eles a certeza de que as referidas teorias explicativas não evoluíram de forma linear, mas sim no confronto de idéias, na disputa por interesses e manutenção de poder - com avanços, longas estagnações e retrocessos constantes.

No que se refere à epidemiologia moderna, Susser e Susser (1998) explicam que esta foi tomando forma no contexto das misérias do século XIX, quando a Inglaterra se constituía como vanguarda da industrialização e urbanização. A partir de então, avaliam existir ao menos três eras na epidemiologia.

Na primeira delas, a era das estatísticas sanitárias, prevaleceu a teoria dos miasmas durante a maior parte do século XIX. As estatísticas revelaram a elevada incidência de doença e morte nos bairros pobres da Inglaterra, França, Alemanha, Escandinávia e EUA. A hipótese dos miasmas era que as causas ambientais emanações pútridas originárias do solo, água e ar - provocavam envenenamento da população e esperava-se que estas fossem reduzidas pela aplicação de sistemas de esgoto e drenagem, coleta de lixo, banhos públicos e melhoria das habitações (o que de fato ocorreu) e em conseqüência, a pobreza pudesse ser "banida" (o que não ocorreu). Havia, também, vozes dissonantes dessa teoria, que explicavam o fato de outra maneira, compreendendo que a pobreza era a causa e não conseqüência daquele contexto sanitário. Apesar do desacordo, era consenso que estas questões eram sociais e que as medidas adequadas para resolvê-las deveriam atingir toda a sociedade.

Neste período, na Inglaterra, os epidemiologistas foram apoiados para realizar mapeamento sobre o excesso de mortalidade no país, em relação às condições de habitação, cuidados com a infância e doenças específicas. Estudaram atividades produtivas, realizando inquéritos nacionais sobre condições de alimentação, infestação por parasitas e respectiva contaminação alimentar. Dessa forma, deram importante contribuição para melhoria das condições de saúde da população, apesar de estarem equivocados quanto às especificidades biológicas, ou seja, em suas teorias sobre emanações

Movimento, Porto Alegre, v. 14, n. 01, p. 39-61, janeiro/abril de 2008. 
pútridas. Na oportunidade, já ocorriam os avanços da microbiologia e suas teorias não conseguiram resistir a este novo paradigma.

No início dos trabalhos realizados por Louis Pasteur sobre a epidemia que afetava bichos-da-seda - cuja causa identificada eram organismos vivos -, e por estudos realizados com humanos acerca da transmissão do cólera, tuberculose, carbúnculo e hanseníase confirmando a existência de seres microscópicos observáveis em laboratório, o novo paradigma que se estabeleceu foi o da Teoria do Germe, perspectiva restrita a modelo de causalidade em que agentes específicos eram relacionados, um a um, a doenças específicas, perdurando este enfoque como hegemônico até metade do século XX (SUSSER; SUSSER, 1998).

Nesse sentido, agentes específicos eram identificados com base no isolamento e na cultura dos locais afetados por doenças causadas por microorganismos, na reprodução experimental e na reprodução de lesões. As respostas visavam a evitar a transmissão por meio de vacinas, isolamento dos pacientes e, em última instância, pela administração de quimioterápicos e antibióticos. Assim, a teoria dos miasmas foi gradativamente relegada ao esquecimento, ocorrendo conjuntamente o declínio da epidemiologia das populações, das exposições ambientais e da dinâmica social das doenças, sendo substituída pela ênfase ao controle dos agentes infecciosos.

Se até hoje não restam dúvidas de que os formuladores da Teoria do Germe estabeleciam relações causais precisas para muitas doenças, cabe observar que sua visão estreita retardou o uso criativo de suas descobertas em prol do progresso efetivo da ciência epidemiológica, havendo aqueles que afirmam que o declínio das doenças infecciosas nos países desenvolvidos deve-se mais à nutrição ou melhoria dos padrões de vida da sociedade do que aos avanços científicos da época.

Ao se estabelecer nova configuração geopolítica planetária decorrente do final da Segunda Guerra Mundial, sobreveio a ascensão das doenças crônicas sobre as infecciosas em países que reestruturavam sua forma de produção, dando continuidade ao projeto capitalista. Orientado pela lógica do lucro e acumulação na qual o trabalhador é progressivamente alienado de seu trabalho,

Movimento, Porto Alegre, v. 14, n. 01, p. 39-61, janeiro/abril de 2008. 
devendo executar tarefas que outros conceberam sem compreender sua destinação social (RIGOTTO, 1993; AUED, 1999), o resultado foi a crescente degradação das condições de saúde da classe operária, o que insuflou aspirações para re-inserção das discussões da causalidade como decorrente das contradições sociais. Em que pesem os gritos da classe trabalhadora na Inglaterra, naquele país as respostas dadas pelo Parlamento foram, ao mesmo tempo, medidas restritivas à organização da categoria, bem como leis que viriam minimizar os danos ocupacionais que deterioravam a força de trabalho (FACCHINI, 1993), sem que a essência do capitalismo e, por conseguinte, as forças determinantes da degradação da saúde, fossem alteradas.

Contribuindo para a falência do paradigma que vigia à época, os antibióticos e quimioterápicos utilizados não se prestavam a combater os agravos do padrão emergente. Também, com o passar do tempo, notou-se que os medicamentos disponíveis não eram o fator primordial para o contínuo declínio das moléstias infecciosas, como se acreditava. Assim é que se assinala o início da era da doença crônica e do correspondente paradigma da caixa-preta, pois naquele momento a ascensão da mortalidade por doenças crônicas já ultrapassara as decorrentes das infecto-contagiosas. As doenças crônicas que ameaçavam de forma mais explícita a saúde pública tornaram-se o objeto primordial da investigação epidemiológica e os grupos estudados foram recrutados entre aqueles sob risco manifesto.

Baseado em estudos de caso-controle e coorte sobre as relações entre fumo e câncer de pulmão, e nos primeiros estudos de coorte sobre a doença coronariana, que definiram o colesterol sérico e tabagismo como fatores de risco, o paradigma da caixa preta relacionava exposição a resultado, "[...] sem que isso implicasse qualquer obrigação de interpolar fatores intermediários, ou mesmo a patogênese, embora nem todos negligenciassem esta interpolação" (SUSSER; SUSSER, 1998, p.195).

De fato, na caixa preta, o tratamento dado à realidade, aos acontecimentos do mundo vivido, destaca atenção aos chamados fatores de risco com vistas a isolá-los para melhor compreensão e

Movimento, Porto Alegre, v. 14, n. 01, p. 39-61, janeiro/abril de 2008. 
intervenção, atomização essa (GONÇALVES; GONÇALVES, 1988) que torna as dimensões psíquicas e sociais passíveis de assumir nivelamento aos atributos biológicos. Isto faz com que, por exemplo, ações de poder autoritário, péssimas condições estruturais, inacessibilidade a bens materiais e perda de hábitos pessoais considerados "saudáveis" possam ser extraídos de seu contexto político, desconsiderando-se que populações não são apenas coleções de indivíduos convenientemente agrupados, mas configuram entidades históricas, com sua própria cultura, organização e divisões sociais e econômicas (PEARCE, 1997).

\section{LIMITES OPERACIONAIS DO RISCO: O QUE PODE E O QUE NÃO PODE SER CALCULADO}

$\mathrm{Na}$ Epidemiologia tradicional ou dos fatores de risco está presente na maior parte dos estudos a intenção de tornar mensuráveis as incertezas. Neste enfoque, podem ser considerados dois tipos de risco: um relativo à percepção vivida - incerteza não-mensurável, e outro referente à incerteza mensurável, passível de quantificação por meio de leis probabilísticas (CASTIEL, 1994). Pode-se exemplificar a primeira forma pela noção de perigo ao se enfrentar francamente um leão faminto, ou saltar sem proteção de altura elevada, situações em que não se tem que fazer grande esforço para prever seus resultados, devido às comparações com acontecimentos pregressos (cujas experiências não precisam ser necessariamente as nossas) que nos dão a dimensão dos efeitos possíveis. Por sua vez, no caso da incerteza mensurável, são utilizados modelos matemáticos que possibilitam estabelecer quantificação, sendo estimadas taxas de risco.

Assim, uma das características básicas do enfoque é sua imprecisão conceitual, que varia conforme as definições de saúde, os propósitos e contextos de sua aplicação, bem como pelos métodos de mensuração empregados. Trata-se de "[...] construção mental que relaciona ações e circunstâncias de hoje com eventual resultado futuro" (BRICEÑO-LEÓN, 1998, p.127). Em termos práticos,

Movimento, Porto Alegre, v. 14, n. 01, p. 39-61, janeiro/abril de 2008. 
a lógica de sua aplicação se dá pela indução, ou seja, é a partir de dados epidemiológicos de determinados grupos populacionais que se projeta a possibilidade ampliada de pessoas, inseridas em outra realidade - quando guardadas algumas semelhanças - virem a sofrer os mesmos danos. Essas características semelhantes podem ser, para nossos interesses, por exemplo, o grau de participação em atividades esportivas, o que explica, em parte, a luta contra o sedentarismo na atualidade.

Pelo estabelecimento dos riscos e as projeções de ocorrência se prescrevem tentativas de prevenção, retroalimentando políticas públicas e buscando influenciar comportamentos individuais. Em que pesem as virtudes e acertos deste enfoque, muitos por sinal, sua sedutora e aparente funcionalidade tem sido bastante questionada, sob variados prismas.

Questão que antecede e se sobressai às demais é a ideológica, porque, nesse aspecto, tal abordagem tem contribuído para conservação de velhas estruturas de dominação entre classes sociais e orientado ações que favorecem o seu emprego como categoria submetida à crescente medicalização. Segundo Castiel (1994, p.155), isto resulta:

[...] de redução que poderíamos chamar de tipo pragmático-funcional. Dessa forma, o risco adquire o estatuto de entidade passível de intervenção e, com isso, geradora do consumo de ações ditas terapêuticas e preventivas específicas [...].

Com relação às associações com a preservação de interesses político-econômicos espoliadores da classe operária, a expressão risco denota possibilidade tanto de ocorrência, quanto de não-ocorrência dos fenômenos ligados à saúde-doença. Induz-se a acreditar, no exemplo dos trabalhadores, que estes podem sofrer danos em suas atividades produtivas, como também podem vir a não sofrêlos, restando sempre margem para dúvida.

Desta forma, se desnuda a identidade do risco como carregada, ao mesmo tempo, de objetividade e subjetividade, sendo que o atributo da dúvida joga com o imaginário, a necessidade, o medo e o prazer

Movimento, Porto Alegre, v. 14, n. 01, p. 39-61, janeiro/abril de 2008. 
do desafio. Portanto, poderíamos considerar até mesmo que o anúncio do risco carrega consigo potencial de ampliação da ocorrência de danos à saúde, pois há os que queiram (e os que precisam por condição de sobrevivência!) desafiar seus limites; em outra situação, pensar que algo sempre está por vir assume feições de irrealidade, pois não é tangível, alcançável. Ora, se o cálculo de risco é feito com dados da vida de outros, pode-se pensar que "isso não irá acontecer comigo", mesmo que todas as evidências reforcem o contrário. Constatação que vale inclusive para os trabalhadores do esporte (atletas), em suas tentativas permanentes de superar seus próprios limites.

Nesta perspectiva, sugere-se que as possibilidades objetivas se ampliam ou reduzam a depender do controle do ambiente, e/ou das condições de vida dos envolvidos, bem como de seus atos inseguros (ou seja, do comportamento de risco). O efeito prático desse pensamento, como já dissemos, são medidas reformistas de prevenção, visando a proteger prioritariamente a atividade produtiva, apesar do anúncio de ênfase no resguardo da saúde das pessoas. Esta lógica favorece a perpetuação de sistema que tem como inerente a possibilidade de causar danos aos trabalhadores, pois, agindo-se no nível de superficialidade, não se altera a essência dos processos em que se originam esses problemas. Fica implícita a idéia de que viver é um risco e que, portanto, é normal conviver com a possibilidade de agressões do trabalho e, grosso modo, deveremos nos contentar com as promessas de redução dos riscos ao mínimo possível.

Outro aspecto problemático que se apresenta na essência desse constructo científico é a atribuição de responsabilidade pelo estado de saúde-doença diretamente às pessoas, na medida em que determinados comportamentos e condições de vida são analisados como resultantes da ignorância e falta de disposição para enfrentamento das adversidades, não levando em conta que a forma de ser é construída na interação com os outros e com o ambiente, num mundo de relações dinâmicas e repleto de antagonismos, e que as tomadas de decisão não dependem apenas da racionalidade e

Movimento, Porto Alegre, v. 14, n. 01, p. 39-61, janeiro/abril de 2008. 
força de vontade. Esse equívoco, geralmente intencional, destinado a encobrir com cortina de fumaça os interesses poderosos, é já amplamente conhecido nos campos da Saúde Pública e Saúde Coletiva como culpabilização da vítima, de forte contravenção ética.

Podemos concluir que o conceito risco é discutível, pois guarda identidade com o possível e o previsível, na conjetura de que o previsível é identificável e quantificável por meio das técnicas probabilísticas, acentuando, em princípio, dimensão preditiva das disciplinas que the fazem uso (AYRES, 2005).

\section{EPIDEMIologia CRítica e a superação do enfoque de RISCO NA EduCAÇÃo FísICA}

Dentre os muitos autores que contribuíram para a re-significação do social no campo da Saúde, vamos destacar as elaborações de um dos principais pensadores contemporâneos da chamada Epidemiologia Crítica (EC), o equatoriano Jaime Breilh, integrante do Centro de Estudos e Assessoria em Saúde, situado em Quito. Trata-se de compreensão de ciência e saúde a partir de um novo projeto epistemológico, ontológico e praxiológico que luta pela emancipação popular, comprometido com a ética pela vida digna dos "sem poder".

Na EC, a epidemiologia é entendida como conjunto de conceitos, métodos e formas de atuação prática que se aplicam ao conhecimento e transformação da saúde-doença em sua dimensão coletiva (ou social), tendo como objeto os processos que determinam a produção de condições específicas de saúde e doença. Situa-se, portanto, nas conseqüências dos processos de deteriorização "[...] ocorridos no trabalho e consumo das classes sociais e sua frações, processos estes vinculados à reprodução geral da estrutura capitalista e às condições políticas e culturais que dela derivam" (BREILH, 1991, p.40). Visa superar formas convencionais e limitantes de determinismos, tanto advindas do positivismo científico, quanto da interpretação do marxismo que circunscreve e submete a dinâmica social às formas de domínios materiais.

Movimento, Porto Alegre, v. 14, n. 01, p. 39-61, janeiro/abril de 2008. 
A discussão de Breilh (1997) avança na seguinte direção: i) existem efetivamente riscos nos centros laborais, mas eles não cobrem a totalidade dos processos determinantes; ii) a organização e divisão do trabalho não se explica adequadamente pelo conceito de risco porque se constitui processo determinante de caráter necessário e permanente e não em simples perigo contingente ou provável; iii) o conceito dificilmente pode dar conta do caráter contraditório do trabalho, que não é absolutamente destrutivo nem absolutamente benéfico; e iv) o uso da palavra risco no contexto convencional está fortemente associado à noção restritiva e estática dos fenômenos nocivos das atividades laborais.

Com isto o autor desenvolve, em substituição, o conceito processo:

[...] que traduz o dinamismo da realidade [e fala em] processos destrutivos e processos favoráveis ou protetores para referir-se ao conjunto de determinantes que condicionam epidemiologicamente o trabalhador, seja no espaço produtivo ou no de consumo e na qüotidianeidade [...] (BREILH, 1997, p.98).

Neste contexto, reforça a necessidade de se investigar a realidade objetiva pelo enfoque dialético, para que sejam apreendidos todos os determinantes da saúde e suas contradições, demonstrando “[...] suas múltiplas e cambiantes possibilidades, sem se prender a problemas convencionais que com freqüência podem ser absorvidos pelo discurso patronal" (BREILH, 1997, p.100).

$\mathrm{Na}$ tentativa de articulação entre diferentes níveis da realidade, delimita os processos particulares que participam da saúde-doença, suas relações e hierarquia interna, buscando "[...] definir o lugar e a importância relativa que podem ocupar as disciplinas gerais no desenvolvimento dos conteúdos científicos particulares do campo da saúde" (BREILH, 1991, p.197).

Quanto ao caráter contraditório do trabalho, Breilh (1997) afirma que os aspectos protetores e destrutivos estão em constante oposição, em todos os níveis da vida social (da superestrutura à singularidade dos sujeitos), e como as pessoas trazem heranças

Movimento, Porto Alegre, v. 14, n. 01, p. 39-61, janeiro/abril de 2008. 
biológicas diferentes e são formadas em ambientes peculiares, mesmos estímulos vão produzindo efeitos também diferentes; assim, saúde-doença passa a ser estado circunstancial, produto destes movimentos e oposições constantes de todas as dimensões da vida. Em nosso entendimento, de forma ilustrativa, poderíamos falar em saldo de conta corrente, em que simultânea e permanentemente há créditos e débitos que dão caráter dinâmico ao status do correntista. A Figura 1 apresenta modelo a respeito:

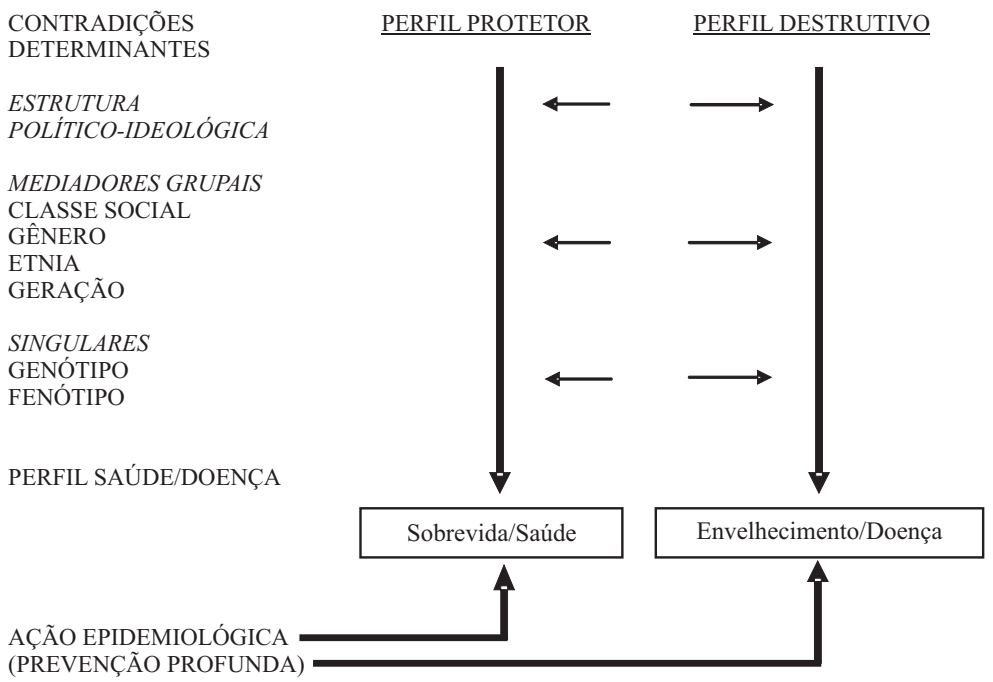

Figura 1 - Modelo para estudo das contradições determinantes da saúde doença Fonte: Breilh, J. Nuevos conceptos y técnicas de investigación: guia pedagógica para un taller de metodología. Quito: Ediciones CEAS, 1997.

Há outras mudanças conceituais importantes: ao invés do convencional exposição (a fatores de risco), usado para se referir à situação em que se está passível de acometimento de acidentes, doenças, morte, prefere-se o termo imposição, pois tantas vezes não se tem liberdade para fazer escolhas, ocorrendo submissão a processos que, sem dúvida, geram destruição da saúde. É neste contexto, por exemplo, que operários esforçam-se por cumprir

Movimento, Porto Alegre, v. 14, n. 01, p. 39-61, janeiro/abril de 2008. 
rigorosamente o estabelecido pelas chefias, mesmo quando têm clareza das condições insalubres e indignas do trabalho, na medida em que o temor pelas represálias é muito presente em tempos de elevado desemprego e poder concentrado dos capitalistas.

Em termos práticos, Breilh (2006) explica que se aplicássemos a lógica de interpretação dos fatores de risco em um cenário de exploração monopolista, como é a agroindústria de flores no Equador, estaríamos admitindo que o aumento das exigências para produção de milhares de "flores perfeitas" para exportação, constitui apenas um risco para a saúde dos trabalhadores. Esse fato é, equivocadamente, considerado externo às suas vidas, como se a agressão fosse ocasional, quando, na verdade, faz parte de um processo altamente insalubre e permanente na reprodução social dos camponeses e inscrito na lógica dominante dos monopólios do setor (BREILH; CAMPAÑA; HIDALGO et al., 2005).

Caminhando para a conclusão, avaliamos ser interessante refletir sobre alguns aspectos da ginástica laboral (GL) - uma das expressões mais destacadas da atividade física relacionada à saúde - e sobre a forma como esta vem sendo proposta no mundo do trabalho. Orientados pelos referenciais da EC, neste exercício, é também possível discutir alternativas para superação da lógica dos fatores de risco tomando como referência o contexto do setor bancário.

Nesse sentido, no Brasil, o marco de desenvolvimento desse setor está atrelado à ditadura militar, na medida em que o golpe foi articulado entre banqueiros e industriais com capitalistas estrangeiros, visando a combater a organização e força política conquistadas na época pelos trabalhadores (MICK, 1995). Ao final dos anos oitenta, sendo favorecido pelo longo período em que vigoraram os altos índices de inflação, obteve-se plenas condições para que no país se instalasse o maior e mais complexo sistema financeiro da América Latina (FEBRABAN, 2005).

$\mathrm{Na}$ atualidade, o sistema financeiro tem papel de destaque no amplo processo de globalização e tem pressionado governos para adoção de medidas que lhe favoreça (MINELLA, 1997), participando na direção de vários órgãos de representação de classe; no financiamento de candidaturas no parlamento e no executivo e

Movimento, Porto Alegre, v. 14, n. 01, p. 39-61, janeiro/abril de 2008. 
influenciando nas decisões políticas em todas esferas da administração pública.

Tendo em vista tamanha concentração de capital ${ }^{1}$ e poder, as reestruturações dos bancos nacionais (optando pela terceirização; intensificação/precarização do trabalho e substituição de milhares de seres humanos por máquinas), as quais determinam as condições de vida e de saúde dos trabalhadores ${ }^{2}$ (SEGNINI, 1999), não podem ser compreendidas como fato isolado ou obra do acaso, mas sim como inerentes aos processos de reestruturação e expansão do próprio capitalismo.

Quanto aos impactos na saúde, a automação e intensificação do trabalho provocaram a evolução das LER $^{3}$ (Lesões por Esforços Repetitivos), com enorme crescimento na década de noventa, fato que exigiu freqüentes negociações coletivas pela organização sindical.

Outro impacto importante refere-se aos transtornos mentais. Conforme dados da Agência Brasil (2006), dos 2.609 bancários de 28 diferentes bancos públicos e privados no país, mais de $40 \%$ sofriam agressões morais no trabalho e $30,52 \%$ se sentiam estressados. De 2000 a 2004, o Instituto Nacional de Seguridade Social (INSS) divulgou o aumento de $65 \%$ no número de diagnósticos com transtornos mentais (SINDICATO..., 2006).

Considerando a extrema complexidade desta situação, na qual os patrões detêm poderes suficientes para oprimir a classe

\footnotetext{
${ }^{1}$ O Jornal Correio do Povo (2006) informou que em 2005 os sete maiores bancos brasileiros arrecadaram juntos, em tarifas, aproximadamente $\mathrm{R} \$ 31$ bilhões; isto significa mais que a arrecadação total dos Estados brasileiros (perdendo apenas para o de São Paulo). O líder do segmento, com faturamento superior ao de bancos importantes dos EUA, poderia cobrir com a receita das tarifas a despesa orçamentária de Roraima por uma década (CORREIO..., 2006). ${ }^{2}$ Desde a década de sessenta os bancos passam por intensa informatização e automação. Porém, isto não significou melhores condições de trabalho, pois seus funcionários são cada vez mais pressionados a trabalhar muitas horas, com rebaixamento salarial e em ritmo de elevada produtividade e concorrência interna. Rigotto (1998) explica que em 1990 os trabalhadores do sistema financeiro brasileiro representavam 1,7 milhões e em 1995 esse número foi brutalmente reduzido para 400 mil, ou seja, mais de um milhão de pessoas desempregadas em apenas cinco anos! Por sua vez, estudo de Xavier (1998) mostra que, no período de 1993 a 1995, um bancário se suicidou a cada quinze dias.

${ }^{3} \mathrm{Em}$ 1997, com a nova Norma de Avaliação de Incapacidade do INSS, as LER passam a se dominar DORT (Distúrbios Osteomusculares Relacionados ao Trabalho). No entanto, segundo Verthein; Minayo-Gomez (2000), este posicionamento tem como pressuposto a descaracterização da relação doença e trabalho, sugerindo que o sujeito é predisposto a adoecer.
}

Movimento, Porto Alegre, v. 14, n. 01, p. 39-61, janeiro/abril de 2008. 
subalternizada de diferentes formas, é mesmo importante analisar como a Educação Física se defronta a esses problemas.

Passando então a tratar da GL, é possível afirmar que de forma geral esta proposta é muito limitada para atender as necessidades dos trabalhadores, pois é dedicada prioritariamente à capacitação para o desempenho profissional, para que eles produzam mais, adoeçam menos e assim, custem pouco para os empresários. Dessa forma, seus proponentes precisam "negociar" seu formato de acordo com as ideologias, rotinas, tempos, ritmos, enfim, com tudo aquilo que faz parte do sistema produtivo da empresa e que são determinados e determinantes do capital. Em outras palavras, a GL precisa se adaptar a um espaço que na verdade tem como função precípua acumular lucros e, para isto, explora a força de trabalho humana.

Embora o volume de publicações a respeito da GL ainda não seja amplo (ALVAREZ, 2002; LONGEN, 2003), pode-se notar facilmente em algumas existentes como se dá esta adaptação e a quê, em síntese, ela se propõe:

w A GL consiste na aplicação de exercícios diários que visam normalizar capacidades e funções corporais para o desenvolvimento do trabalho, diminuindo a possibilidade de comprometimento da integridade do corpo (POLITO; BERGAMASCHI, 2002) e;

w Esta proposta pode ser conceituada como um conjunto de práticas físicas, elaboradas a partir da atividade profissional exercida durante o expediente, que visa compensar as estruturas mais utilizadas no trabalho e ativar as que não são requeridas, relaxando-as e tonificando-as (LIMA, 2003).

Confirmando esta tendência, bastante aderente à lógica dos fatores de risco, no estudo de Mazzola (2003) sobre empresas que adotaram GL, concluiu-se que a saúde e qualidade de vida dos trabalhadores são secundárias, priorizando-se a diminuição da ocorrência de acidentes de trabalho e de doenças ocupacionais. Este autor avalia que os empregados acreditam na implantação da GL para atender as necessidades produtivas, como por exemplo, "aumentar seu desempenho profissional"; "elevar níveis de

Movimento, Porto Alegre, v. 14, n. 01, p. 39-61, janeiro/abril de 2008. 
produtividade"; "diminuir o número de faltas e de atestados" e "reduzir os problemas relacionados às LER".

É possível também afirmar que os benefícios destacados pelas definições da GL referem-se a qualquer contexto, independente se a proposta é dirigida para os trabalhadores bancários, metalúrgicos ou coletores de lixo, portanto, independentemente de suas especificidades laborais e necessidades enquanto indivíduos e classe. É notório como as propostas limitam-se ao ambiente de trabalho (as aulas de GL são de, aproximadamente, cinco a dez minutos), focalizando suas ações na compensação das estruturas exigidas no ato laboral e não nos determinantes destes desgastes, ou seja, a estrutura de poder do capital que atua, sobretudo, nas consciências dos trabalhadores. Desta forma, a GL se revela como fundamentada em aportes teórico-metodológicos funcionalistas e de utilidade para modelos de gestão neoliberal, aquilo que Breilh (2006) denomina de mudanças "cosméticas", pois deixam intactas as estruturas insalubres.

$\mathrm{Na}$ medida em que os problemas dos trabalhadores são considerados como algo externo, devendo ser resolvidos fora do espaço controlado pela empresa, busca-se minimizar as relações muitas vezes tensas do ambiente laboral através de atividades de integração, evitando-se destacar as contradições próprias dessas relações humanas. Corroborando com esta reflexão, Mazzola (2003) constatou que a GL representa uma estratégia de redução de conflitos entre capital e trabalho, para que os funcionários se sintam mais "protegidos" e "beneficiados" pela empresa.

Enfim, pode-se dizer que da forma como a GL vem sendo desenvolvida hegemonicamente, ela representa muito mais uma maneira de acomodação das tensões sociais; de dissipação das fortes contradições do processo produtivo; de despolitização do ato laboral e desmobilização da luta sindical; de individualização da conquista pela saúde e de compensação paliativa aos desgastes físicos e psíquicos dos trabalhadores. Afinal, a GL também vem sendo identificada como ginástica compensatória...mas, compensatória a quê, senão à entrega da saúde ao processo produtivo!?

Portanto, havendo o interesse em contribuir para a superação de modelos idealizados e padronizados da GL, freqüentemente

Movimento, Porto Alegre, v. 14, n. 01, p. 39-61, janeiro/abril de 2008. 
oferecidos como atividade de baixo custo e boa efetividade na conquista da saúde, é preciso buscar fundamentos em diferentes campos de conhecimento, aprofundando estudos sobre o mundo do trabalho (ALVES, 2005; ANTUNES, 2003; MÉSZÁROS, 2002); saúde do trabalhador (LACAZ, 2000; MINAYO-GOMEZ; THEDIM-COSTA, 2003); sindicalismo (ANTUNES, 2005; BOITO JÚNIOR, 1991; GIANNOTTI, 1991); qualidade de vida e atividade física (GONÇALVES; VILARTA, 2004) e educação física e saúde coletiva (FRAGA; WACHS, 2007).

Nesta perspectiva, ao invés de se estabelecer a priori as necessidades de saúde e propor aos dirigentes dos bancos um programa de exercícios (ginástica laboral para o combate ao sedentarismo e compensação aos desgastes provocados pelos gestos repetitivos e intensos), torna-se fundamental valorizar o conhecimento da organização coletiva e partir do diálogo - cuidadoso e demorado - com as organizações de classe ${ }^{4}$ (a princípio representantes legítimas dos trabalhadores) para identificar suas principais pautas de luta, inclusive no âmbito da saúde.

Uma das categorias da EC, a reprodução social ${ }^{5}$ (CAMPAÑA, 1997), permite compreender que: i) o trabalho é determinante no processo saúde-doença e por esta razão é importante investigar para além do que as aparências indicam e ii) neste contexto, as pessoas não são somente expostas a riscos à sua saúde, mas sim impostas a um processo extremamente insalubre, devido principalmente ao acúmulo dos poderes do sistema financeiro e à insuficiência de mecanismos de defesa coletivos que se contraponham efetivamente aos desgastes físicos e psíquicos decorrentes da exploração.

Na consolidação de uma nova possibilidade de intervenção da Educação Física, superadora das tendências da GL, é desejável a

\footnotetext{
${ }^{4}$ Para Demo (1996), a organização sindical é um canal decisivo de participação e organização da sociedade civil. É importante que os trabalhadores percebam seus direitos fundamentais, tais como trabalhar para usufruir nível de vida acima de mera sobrevivência.

${ }^{5}$ Reprodução social se caracteriza pela forma com que os seres humanos consomem e trabalham; pelas relações sociais que estabelecem; como transformam a natureza; pela distribuição e troca de bens socialmente produzidos; pelas instituições que geram e pela consciência e organização que alcançam.
}

Movimento, Porto Alegre, v. 14, n. 01, p. 39-61, janeiro/abril de 2008. 
identificação dos proponentes como pesquisadores do mundo do trabalho, buscando construir seus conhecimentos pela observação de diferentes espaços e documentos - tais como comunicações de acidentes de trabalho (CAT); as páginas na Internet e impressos de divulgação das atividades dos bancos e sindicatos; jornais e boletins de greve distribuídos nas assembléias da categoria; através de entrevistas realizadas com funcionários e sindicalistas.

No campo da educação sindical, trabalhos como os de Arruda (1990) são importantes porque orientam sobre qual a educação que interessa à classe trabalhadora, possibilitando, em decorrência, auxiliar na reflexão sobre qual projeto político-pedagógico da Educação Física corresponde às suas necessidades. Assim, com vistas a transformar as relações de poder estabelecidas na tensão entre capital e trabalho, este autor preconiza que a educação deve ter como base o ser humano integral, sendo compromisso do educador auxiliar na formação da vontade humana e sua intencionalidade; e contribuir para que ele possa teorizar sobre sua prática, ajudando-o a sair da visão imediatista, ativista e empirista e ir conquistando cada vez mais a visão estratégica e totalizante da realidade.

Para tanto, é fundamental incentivar a participação dos trabalhadores na produção do conhecimento, pois o domínio do saber é uma fonte de poder, o que colabora com o projeto de transformação social. Estando os interesses dos educadores e de suas aulas voltados às necessidades básicas dos sujeitos, é importante considerar suas aspirações e potencialidades de conhecer e agir (BORDA, 1988). É possível auxiliá-los a identificar de maneira crítica seus próprios problemas e a encontrar soluções viáveis para sua superação a partir da organização coletiva e da responsabilização do Estado, das instituições financeiras e do próprio Sindicato.

Por fim, são concepções político-pedagógicas que pretendem avançar na compreensão e adoção de uma ciência comprometida com a transformação das condições de vida e de saúde dos trabalhadores. Obviamente, todo este esforço não representa tarefa simples, tampouco suficiente, na medida em que para além do estudo sistemático do conhecimento contra-hegemônico do campo da saúde

Movimento, Porto Alegre, v. 14, n. 01, p. 39-61, janeiro/abril de 2008. 


\section{Artigos Originais}

Edgard Matiello Júnior, et al.

e as decorrentes abstrações para a realidade da Educação Física, estão também presentes as tensões políticas e os limites humanos e profissionais dos pesquisadores, pois de fato a lógica dos fatores de risco está impregnada em nossos saberes e agires cotidianos, sendo superada somente com o amadurecimento, esforço permanente e o devido apoio de investigadores e instituições decididamente democráticas.

Movimento, Porto Alegre, v. 14, n. 01, p. 39-61, janeiro/abril de 2008. 
Overcoming risks in the physical activity related to health

Abstract: The risk factor's logic which prevails in the epidemiologic investigations from the health field has been reproduced in the Physical Education, specially in a trend hegemonic denominated Physical Activity related to Health. This work aims to present and to discuss the main historical landmarks and to detach effects from this paradigm in this knowledge field. In the end, a form of appropriation of the Critical Epidemiology will be presented with illustrations of overcoming attempt developed with workers from the banking sector.

Keywords: Physical Activity. Public Health. Risk Factors. Epidemiology.

\footnotetext{
Superando riesgos en la actividad física relacionada a la salud

Resumen: La lógica de los factores de riesgo que predomina en las investigaciones epidemiológicas del campo de la Salud viene siendo reproducida en la Educación Física, específicamente en el tendencia hegemónica denominada Actividad Física relacionada a la Salud. En este trabajo el objetivo es presentar y discutir principales marcos históricos y destacar efectos de ese paradigma en esos campos de conocimiento. Al final, será presentada una forma de apropiación de la Epidemiología Crítica como ilustración de tentativa de superación junto a trabajadores del sector bancario.

Palabras-clave: Actividad Física. Salud Pública. Factores de Riesgo. Epidemiología.
}

\section{REFERÊNCIAS}

AGÊNCIA BRASIL. Quase metade dos bancários sofre agressões morais no trabalho, revela pesquisa. 2006. Disponível em: <http:// www.seebfloripa.com.br> Acesso em: 11 de jul. de 2006.

ALMEIDA FILHO, Naomar. A ciência da saúde. São Paulo: Hucitec, 2000.

ALVAREZ, Bárbara Regina. Estilo de vida e hábitos de lazer de trabalhadores, após dois anos de aplicação de programas de ginástica laboral e saúde - Caso Intelbras. 2002. 185f. Tese (Doutorado em Engenharia de Produção)

Movimento, Porto Alegre, v. 14, n. 01, p. 39-61, janeiro/abril de 2008. 
- Programa de Pós-graduação em Engenharia de Produção, Universidade Federal de Santa Catarina, Florianópolis, 2002.

ALVES, Giovanni. O novo (e precário) mundo do trabalho: reestruturação produtiva e crise do sindicalismo. São Paulo: Boitempo, 2005.

ANTUNES, Ricardo. Os sentidos do trabalho: ensaio sobre a afirmação e a negação do trabalho. São Paulo: Boitempo, 2003.

A desertificação neoliberal no Brasil (Collor, FHC e Lula). 2.ed. Campinas: Autores Associados, 2005.

ARRUDA, Marcos. A formação que interessa à classe trabalhadora. Forma e Conteúdo, São Paulo, v.1, p.23-27, 1990.

AUED, Idaleto Malvezzi. Capital e emancipação humana: o ser social. In: AUED, WRUBLEVSKI, Bernadete (Org.). Educação para o (des)emprego. Petrópolis: Vozes, 1999. p.109-131.

AYRES, José Ricardo de Carvalho Mesquita. Acerca del riesgo: para compreender la epidemiologia. 1. ed. Buenos Aires: Lugar Editorial, 2005.

BOITO JÚNIOR, Armando. O sindicalismo brasileiro nos anos 80 . Rio de Janeiro: Paz e Terra, 1991.

BORDA, Orlando Fals. Aspectos teóricos da pesquisa participante: considerações sobre o significado e o papel da ciência na participação popular. In: BRANDÃO, Carlos Rodrigues (Org.). Pesquisa participante. 7. ed. São Paulo: Brasiliense, 1988. p.42-62.

BREILH, Jaime. Epidemiologia: economia, política e saúde. São Paulo: Unesp/ Hucitec, 1991.

Nuevos conceptos y técnicas de investigación: guia pedagógica para un taller de metodología. Quito: CEAS, 1997.

Epidemiologia crítica: ciência emancipadora e interculturalidade. Rio de Janeiro: FIOCRUZ, 2006.

BREILH, Jaime; CAMPAÑA, Arturo; HIDALGO, Francisco et al. La floricultura y el dilema de la salud: por uma flor justa y ecologica. In: BREILH, Jaime. (Ed.). Informe alternativo sobre la salud en América Latina (Observatório Latinoamericano de Salud). Quito: Somos punto y línea, 2005. p.70-83.

BRICEÑO-LEÓN, Roberto. A cultura da enfermidade como fator de proteção e de risco. In: VERAS, Renato Peixoto et al. (Org.). Epidemiologia: contextos e pluralidade. Rio de Janeiro: FIOCRUZ, 1998. p.121-131.

CAMPAÑA, Arturo. Em busca da definição de pautas atuais para o delineamento de estudos sobre condições de vida e saúde. In: BARATA, Rita Barradas (Org.).

Movimento, Porto Alegre, v. 14, n. 01, p. 39-61, janeiro/abril de 2008. 
Condições de vida e situação em saúde. Rio de Janeiro: ABRASCO, 1997. p.115-165.

CASTIEL, Luís David. O buraco e o avestruz: a singularidade do adoecer humano. Campinas: Papirus, 1994.

CORREIO DO POVO. Bancos devem mais de 8 bilhões ao governo. 2006. Disponível em: <http://www.seebfloripa.com.br> Acesso em: 06 mar. 2006.

DEMO, Pedro. Participação é conquista: noções de política social participativa. 3. ed. São Paulo: Cortez, 1996.

FACCHINI, Luís Augusto. Por que a doença? a inferência causal e os marcos teóricos de análise. In: BUSCHINELLI, José Tarcísio Penteado; ROCHA, Lys Ester; RIGOTTO, Raquel Maria (Orgs.). Isto é trabalho de gente?: vida, doença e trabalho no Brasil. São Paulo: Vozes, 1993. p.33-55.

FEBRABAN. Federação Brasileira dos Bancos. Atendimento e serviços. 2005 Disponível em: <http://www.febraban.org.br/Arquivo/Servicos/Dadosdosetor/ atendimento_2005.asp> Acesso em: 12 nov. 2005.

FRAGA, Alex Branco; WACHS, Felipe (Org.). Educação física e saúde coletiva: políticas de formação e perspectivas de intervenção. Porto Alegre: Editora da UFRGS, 2007.

GIANNOTTI, Vito. O que é estrutura sindical. 3. ed. São Paulo: Brasiliense, 1991.

GONÇALVES, Aguinaldo; VILARTA, Roberto (Org.). Qualidade de vida e atividade física: explorando teoria e prática. Barueri: Manole, 2004.

GONÇALVES, Aguinaldo; GONÇALVES, Neusa Nunes da Silva e. Saúde e Doença - Conceitos básicos. Revista Bras. Ciências do Movimento, Brasília, DF, v. 2, n. 2, p. $48-56,1988$.

JINKINGS, Nise. Trabalho e resistência na "fonte misteirosa": os bancários no mundo da eletrônica e do dinheiro. Campinas:São Paulo: Editora da Unicamp, Imprensa Oficial de São Paulo, 2002.

LACAZ, Francisco Antônio de Castro. Qualidade de vida no trabalho e saúde/ doença. Ciência \& Saúde Coletiva, Rio de Janeiro, v.5, n.1, p.151-161, 2000.

LIMA, Valquíria de. Ginástica laboral: atividade física no ambiente de trabalho. São Paulo: Phorte, 2003.

LONGEN, Willians Cassiano. Ginástica Laboral na prevenção de LER/DORT? Um estudo reflexivo em uma linha de produção. 2003. 130f. Dissertação (Mestrado em Engenharia de Produção) - Programa de Pós-graduação em Engenharia de Produção, Universidade Federal de Santa Catarina, Florianópolis, 2003.

MATIELLO JUNIOR, Edgard; GONÇALVES, Aguinaldo. Entre a bricolagem e o personal training ou...a relação atividade física e saúde nos limites da ética. In:

Movimento, Porto Alegre, v. 14, n. 01, p. 39-61, janeiro/abril de 2008. 
CONGRESSO BRASILEIRO DE CIÊNCIAS DO ESPORTE, 12., 2001, Campinas. Anais...Campinas: UNICAMP, 2001. CD-ROM

Saúde Coletiva, atividade física e violências. In: GONÇALVES, Aguinaldo et al. Conhecendo e discutindo saúde coletiva e atividade física. Rio de Janeiro: Guanabara-Koogan, 2004. p.41-60.

MAZZOLA, João Mário. Análise dos Programas de Ginástica Laboral nas empresas: um benefício para os trabalhadores ou para a empresa? 2003. 160f Dissertação (Mestrado) - Programa de Pós-graduação em Desenvolvimento Regional, Universidade de Santa Cruz do Sul, Santa Cruz do Sul, 2003.

MÉSZÁROS, István. Para além do capital. São Paulo: Boitempo; Campinas: Ed. da UNICAMP, 2002.

MICK, Jacques. Sessenta: uma história: 1935 - 1995. Florianópolis: SEEB de Florianópolis e Região, 1995.

MINAYO-GOMEZ, Carlos; THEDIM-COSTA, Sonia Maria da Fonseca. Incorporação das ciências sociais na produção de conhecimentos sobre trabalho e saúde. Ciência \& Saúde Coletiva, Rio de Janeiro, v.8, n.1, p. 125-236, 2003.

MINELLA, Ary Cesar. Elites financeiras, sistema financeiro e governo FHC. In: OURIQUES, Nildo Domingos; RAMPINELLI, Waldir José (Org.). No fio da navalha: crítica das reformas neoliberais de FHC. São Paulo: Xamã, 1997. p. 165-199.

PEARCE, Neil. Classe social e câncer. In: BARATA, Rita Barradas et. al. (Org.). Eqüidade e Saúde: contribuições da Epidemiologia. Rio de Janeiro: FIOCRUZ/ ABRASCO, 1997. p.121-133

POLITO, Eliane; BERGAMASCHI, Eliane Cristina. Ginática laboral: teoria e prática. Rio de Janeiro: Sprint, 2002.

RIGOTTO, Raquel Maria. O homem e o trabalho. In: BUSCHINELLI, José Tarcísio Penteado; ROCHA, Lys Ester; RIGOTTO, Raquel Maria (Org.). Isto é trabalho de gente?: vida, doença e trabalho no Brasil. São Paulo: Vozes, 1993. p.25-32.

Saúde dos trabalhadores e meio ambiente em tempos de globalização e reestruturação produtiva. Revista Brasileira de Saúde Ocupacional, São Paulo, v.25, n.93-94, p.9-20, 1998.

ROSEN, George. Uma história da Saúde Pública. Rio de Janeiro: Abrasco, 1994

SABROZA, Paulo Chagastelles. Prefácio. In: COSTA, Dina Czeresnia (Org.) Epidemiologia: teoria e objeto. São Paulo: Hucitec, Abrasco, 1994. p.7-10.

SEGNINI, Liliana Rolfsen Petrilli. Reestruturação nos bancos no Brasil: desemprego, subcontratação e intensificação do trabalho. Educação \& Sociedade, Campinas, v.20, n.67, p.183-209, ago. 1999.

Movimento, Porto Alegre, v. 14, n. 01, p. 39-61, janeiro/abril de 2008. 
SINDICATO DOS BANCÁRIOS DE PERNAMBUCO. Empregado do Santander com depressão é reintegrado. 2006. Disponível em: <http:// www.seebfloripa.com.br> Acesso em: 10 mar. 2006.

SUSSER, Mervyn; SUSSER, Ezra. Um futuro para a epidemiologia. In: ALMEIDA FILHO, Naomar et. al. (Org.). Teoria epidemiológica hoje: fundamentos, interfaces e tendências. Rio de Janeiro: FIOCRUZ/ABRASCO, 1998. p.256.

VERTHEIN, Marilene Affonso Romualdo; MINAYO-GOMEZ, Carlos. A construção do "sujeito-doente" em LER. História, Ciências, Saúde - Manguinhos, Rio de Janeiro, v.7, n.2, p. 327-345, jul./set., 2000.

XAVIER, Ernani Pereira. Um minuto de silêncio: réquiem aos bancários mortos no trabalho. Porto Alegre: Sindicato dos Bancários de Porto Alegre, 1998. 